EVS28

KINTEX, Korea, May 3-6, 2015

\title{
Modelling and Simulation Study on a Series-parallel Hybrid Electric Vehicle
}

\author{
Li Yaohua, Wang Ying, Zhao Xuan \\ School of Automotive, Chang'an University, Xi'an China \\ E-mail:nuaaliyaohua@126.com
}

\begin{abstract}
Hybrid electric vehicle (HEV) uses internal combustion engine (ICE) and electrical power, so it has the advantages of both ICE vehicle and electrical vehicle (EV) and overcomes their disadvantages. And seriesparallel hybrid is the combination of series and parallel structures, thus it possesses the major features of both and more plentiful operation modes than one of them alone. In this paper, a series-parallel HEV model is built by using Matlab/Simlunk, which constitutes of vehicle longitudinal dynamics model, tire model, an ICE model, battery model, a DC/DC converter model, a motor drive model, a generator drive model, a speed coupling device model (planetary gear mechanism), and a torque coupler device model. Control scheme of HEV is presented. And Simulation results testify the effectiveness of the HEV model.
\end{abstract}

Keywords: Hybrid electrical, Electrical vehicle, Series-parallel hybrid electrical vehicle, Simulation

\section{Introduction}

Conventional vehicle with internal combustion engine (ICE) has the disadvantages of poor fuel economy and environmental pollution, because of mismatch of engine fuel efficiency characteristics with the real operation requirement, dissipation of vehicle kinetic energy during braking, especially while operating in urban areas and low efficiency of hydraulic transmission in stop-and-go driving pattern. Battery-powered electric vehicle (EV) possesses many advantages over ICE vehicle: high energy efficiency and zero environmental pollution, but its operation range per battery charge of is far less competitive than ICE vehicle, due to the much lower energy density of the batteries than that of gasoline. Hybrid electric vehicle (HEV) uses two power sources (ICE and electrical power), which has the advantages of both ICE vehicle and $\mathrm{EV}$ and overcomes their disadvantages. Depending on the power transmission path, HEV can be classified into series hybrid, parallel hybrid, and series-parallel hybrid. Among them, seriesparallel hybrid is the combination of series and parallel structures, which possesses the major features of both and more plentiful operation modes than those of the series or parallel structure alone, thus it has drawn many interests from many automotive companies $^{[1]-[5]}$.

In this paper, a series-parallel HEV model built by using Matlab/Simlunk is presented, which constitutes of vehicle longitudinal dynamics model, tire model, an ICE model, battery model, a DC/DC converter model, a motor drive model, a generator drive model, a speed coupling device model (planetary gear mechanism), and a torque coupler device model. Control scheme of HEV is presented. And Simulation results testify the effectiveness of the HEV model. 


\section{Series-parallel HEV Model}

The diagram of series-parallel HEV model is shown in Fig. 1.

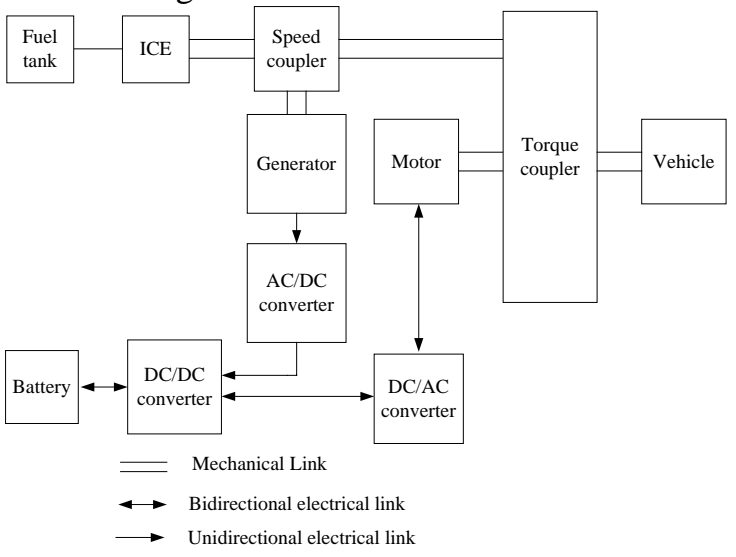

Figure 1: The diagram of series-parallel HEV

The series-parallel HEV model is made up of vehicle longitudinal dynamics model, tire model, an ICE model, battery model, a DC/DC converter model, a motor drive model, a generator drive model, a speed coupling device model (planetary gear mechanism) and a torque coupler device model. Subsequently, we will introduce these subsystems.

\subsection{Longitudinal dynamic model}

The longitudinal dynamic model of the HEV is a two-axle vehicle, with four equally sized wheels, moving forward or backward along its longitudinal axis shown in Fig. 2, where $m$ is vehicle mass, $\beta$ is incline angle, $A$ is effective frontal vehicle cross-sectional area, $V_{x}$ is longitudinal vehicle velocity, $\mathrm{F}_{\mathrm{xf}}$ and $\mathrm{F}_{\mathrm{xr}}$ are longitudinal forces on the vehicle at the front and rear wheel ground contact points, $\mathrm{F}_{\mathrm{zf}}$ and $\mathrm{F}_{\mathrm{zr}}$ are vertical load forces on the vehicle at the front and rear ground contact points, $h$ is height of position of the vehicle's center of gravity above the ground, $a$ and $b$ are distances of front and rear axles, $F_{d}$ is aerodynamic drag force.

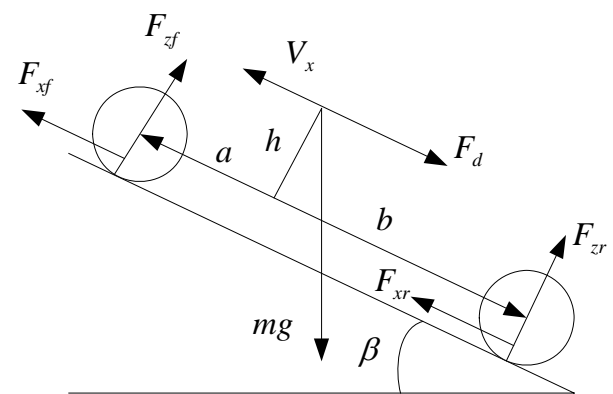

Figure 2: Vehicle dynamics model

According to Fig. 2, we can get (1) and (2). According to (1) and (2), $\mathrm{V}_{\mathrm{x}}$ and $\mathrm{F}_{\mathrm{x}}, \mathrm{F}_{\mathrm{zf}}$ and $\mathrm{F}_{\mathrm{zr}}$ are shown in Fig. 3 and Fig. 4.

$$
\begin{aligned}
& \left\{\begin{array}{l}
m \dot{V}_{x}=F_{x}+F_{d}-m g \sin \beta \\
F_{x}=F_{x f}+F_{x r} \\
F_{d}=-\frac{1}{2} C_{d} \rho A V_{x}^{2} \cdot \operatorname{sgn}\left(V_{x}\right)
\end{array}\right. \\
& \left\{\begin{array}{l}
F_{z f}=\frac{b \cdot m g \cos \beta-h\left(F_{d}-m g \sin \beta-m \dot{V}_{x}\right)}{a+b} \\
F_{z r}=\frac{a \cdot m g \cos \beta+h\left(F_{d}-m g \sin \beta-m \dot{V}_{x}\right)}{a+b}
\end{array}\right.
\end{aligned}
$$

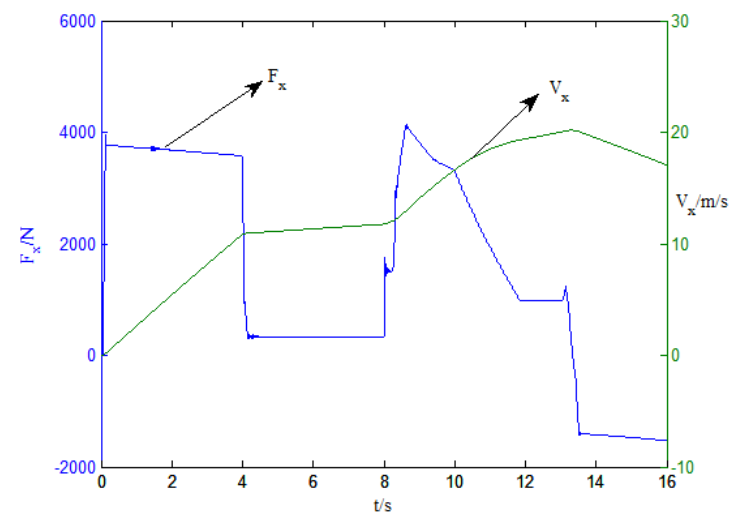

Figure 3: $V_{x}$ and $F_{x}$

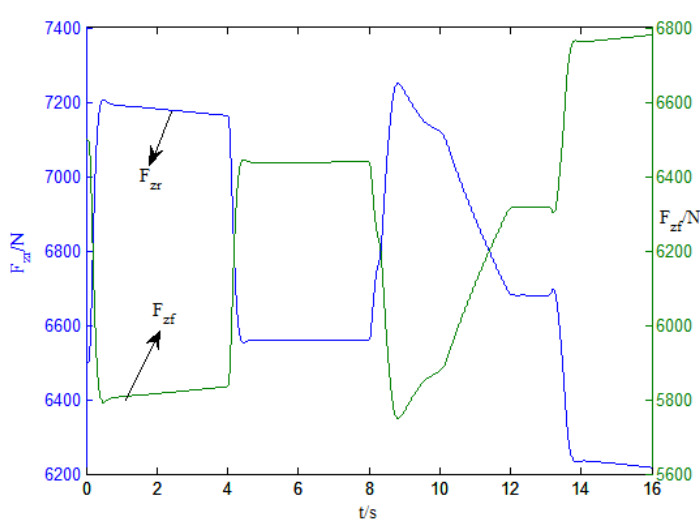

Figure 4: $\mathrm{F}_{\mathrm{zf}}$ and $\mathrm{F}_{\mathrm{zr}}$

\subsection{Tire model}

The tire is a flexible body in contact with the road surface and subject to slip. When a torque is applied to the wheel axle, the tire deforms, pushes on the ground (while subject to contact friction), and transfers the resulting reaction (including rolling resistance) as a force back on the wheel, pushing the wheel forward or backward. The tire model is a rigid-wheel, flexible-body combination in contact with the road. At high speed $(>2.5 \mathrm{~m} / \mathrm{s})$, the tire acts like a damper, and the longitudinal force $F_{x}$ is determined mainly by the slip. At low speed $(<2.5 \mathrm{~m} / \mathrm{s})$, when the tire is starting up from 
or slowing down to a stop, the tire behaves more like a deformable, circular spring.

\subsection{ICE model}

The ICE model is a gasoline-fuel, spark-ignition engine with a speed governor. The engine runs at a variable speed under the control of a throttle signal, which directly controls the output torque that the engine generates and indirectly controls the speed at which the engine runs. Engine speed versus engine peak torque is shown in Fig. 5. Simulation results of ICE are shown in Fig. 6.

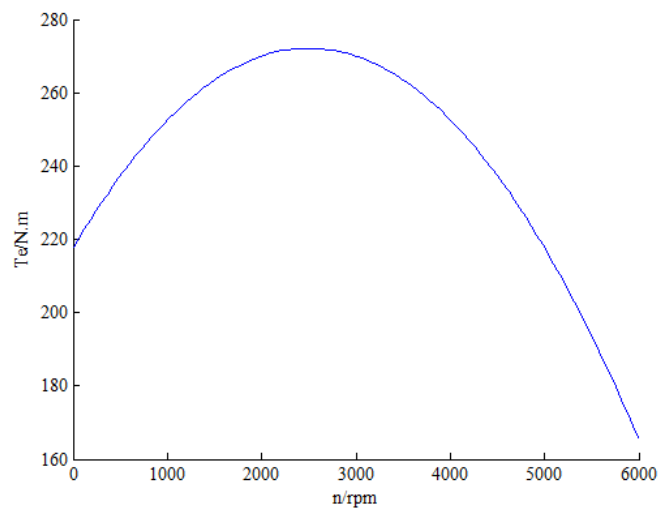

Figure 5: Engine speed versus engine peak torque
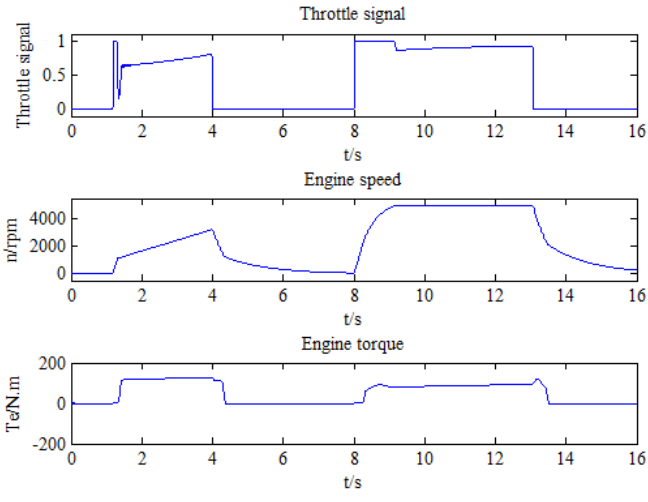

Figure 6: Simulation results of ICE

\subsection{Battery model}

Battery model is a Nickel-Metal-Hydride battery, which uses ampere-hour integration method to calculate State-Of-Charge (SOC) of battery. Simulation results of battery are shown in Fig. 7.
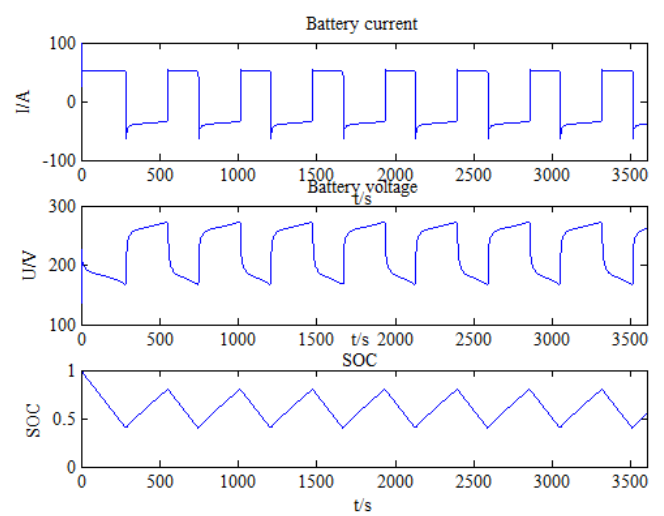

Figure 7: Simulation results of battery

\subsection{DC/DC converter model}

A bidirectional DC/DC converter is used as electronic coupling device, which increases battery voltage to $500 \mathrm{~V}$ and uses a PI controller to keep DC-link voltage constant (500V) during charging and discharging period. Simulation results of DC/DC converter are shown in Fig. 8.

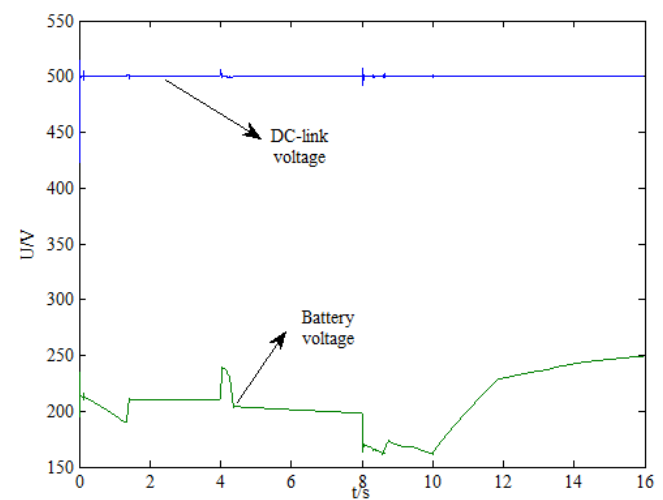

Figure 8: Simulation results of DC/DC converter

\subsection{Motor drive model}

The motor drive is a $50-\mathrm{kW}$ interior permanent magnet synchronous motor (PMSM) drive using vector control. And three-phase stator currents hysteresis control is used to implement vector control. The diagram of motor drive is shown in Fig. 9. And the d-axis and q-axis stator current are shown in Fig. 10. The a-phase stator current is shown in Fig. 11. The motor speed and motor torque are shown in Fig. 12. 


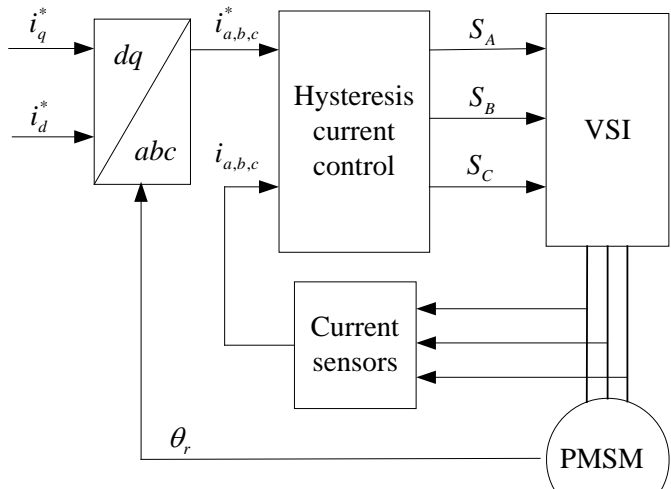

Figure 9: The diagram of motor drive
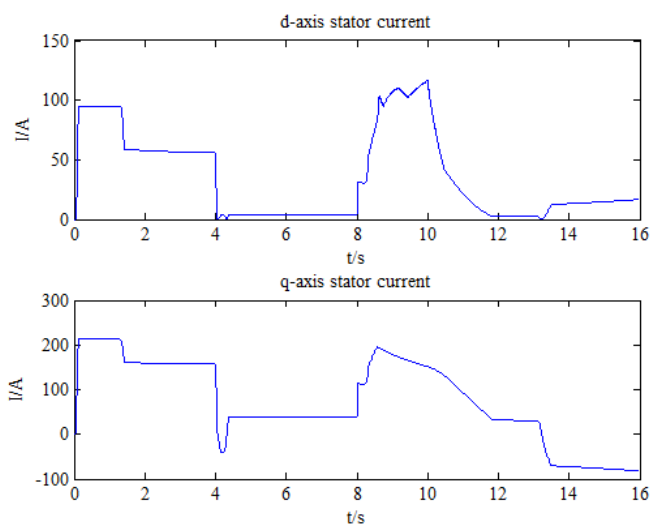

Figure 10: d-axis and q-axis stator current

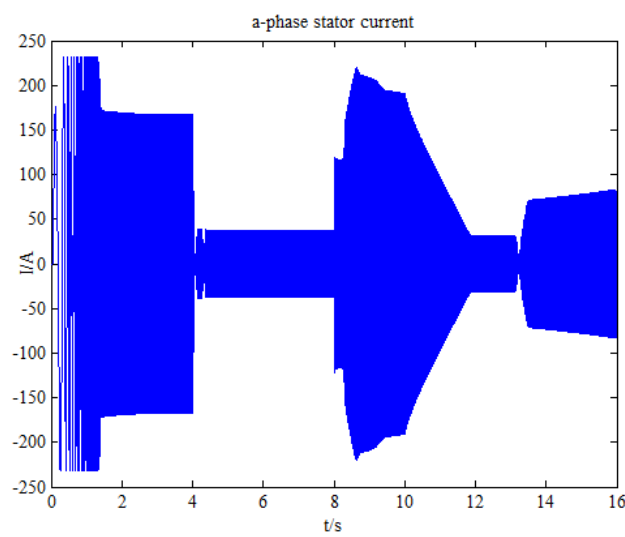

Figure 11: The a-phase stator current
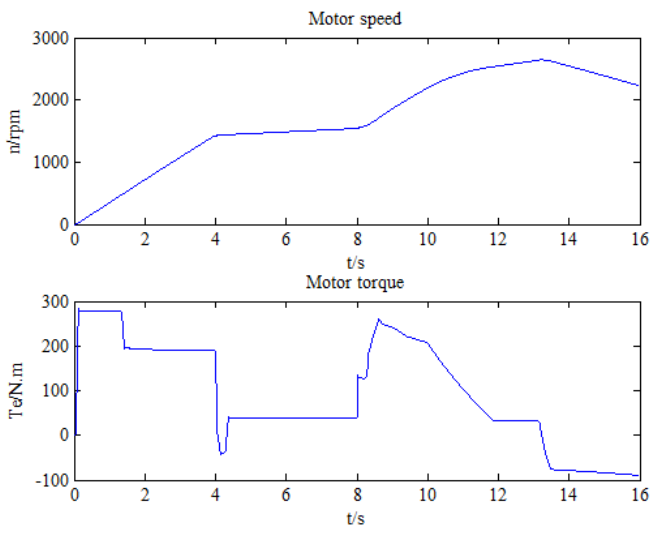

Figure 12: The motor speed and motor torque

\subsection{Generator drive model}

The generator drive is a $30-\mathrm{kW}$ surface PMSM drive, which also uses vector control and threephase stator currents hysteresis control. The reference torque of generator motor drive is negative (generating mode) or zero (free rotating). And the $\mathrm{d}$-axis and q-axis reference stator current are shown in Fig. 13. The a-phase stator current is shown in Fig. 14. The generator speed and generator torque are shown in Fig. 15.
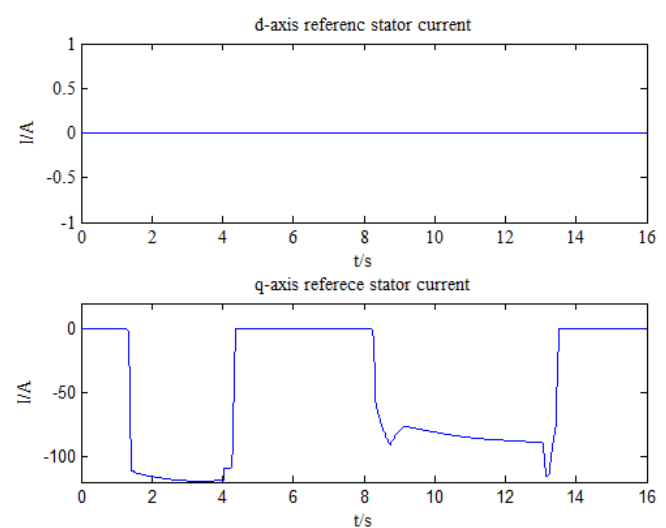

Figure 13: d-axis and q-axis reference stator current

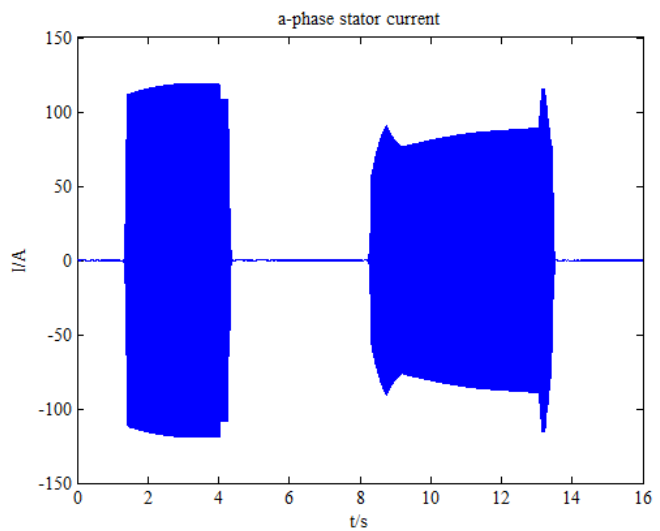

Figure 14: The a-phase stator current
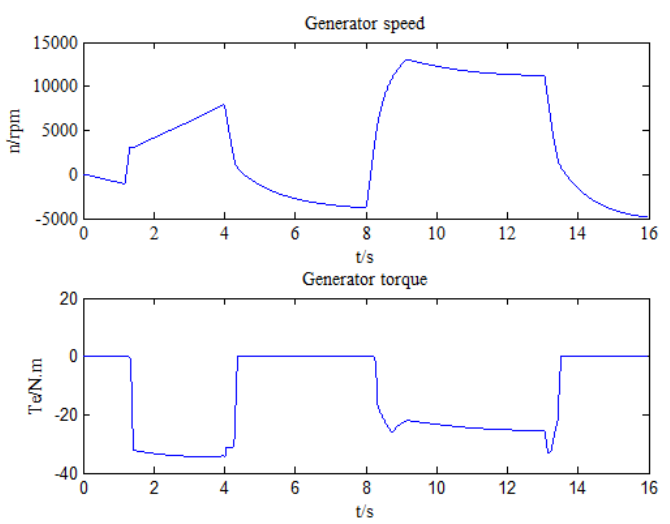

Figure 15: The generator speed and generator torque 


\subsection{Speed coupling device model}

Planetary gear unit is used in HEV model as a speed-coupling device. Planetary gear unit is a three-port, two-degree-of-freedom mechanical device shown in Fig. 16, where Port 1 is connected to an ICE with unidirectional energy flow, Ports 2 is connected to torque coupler with bidirectional energy flow and Port 3 is connected to the generator drive motor with bidirectional energy flow.

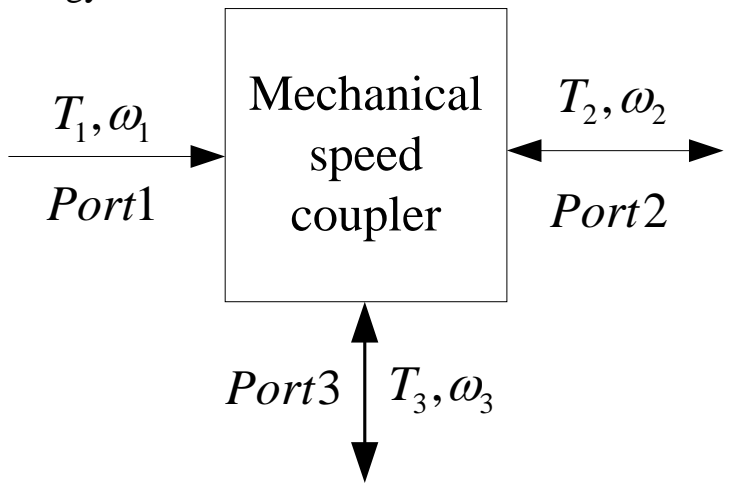

Figure 16: Speed coupling

The mechanical speed coupler has the property shown in (3), where $\mathrm{k}_{1}$ and $\mathrm{k}_{2}$ are constants associated with the structural and geometric design of speed coupling device.

$\left\{\begin{array}{l}\omega_{3}=k_{1} \omega_{1}+k_{2} \omega_{2} \\ T_{3}=\frac{T_{1}}{k_{1}}=\frac{T_{2}}{k_{2}}\end{array}\right.$

Simulation results of planetary gear unit are shown in Fig. 17 to Fig. 19.
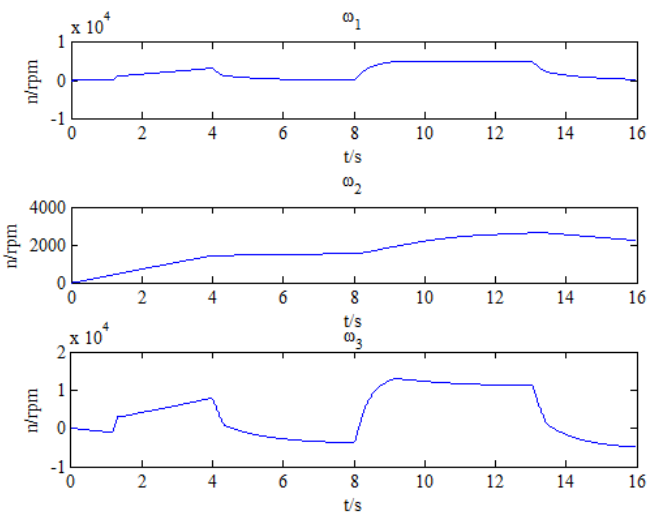

Figure 17: Speed
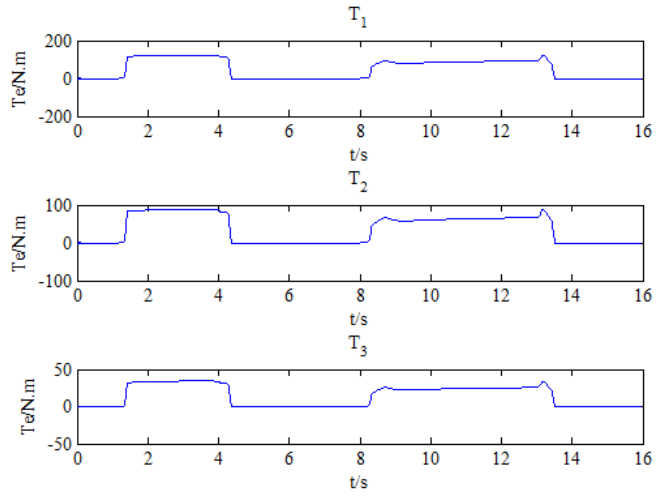

Figure 18: toque

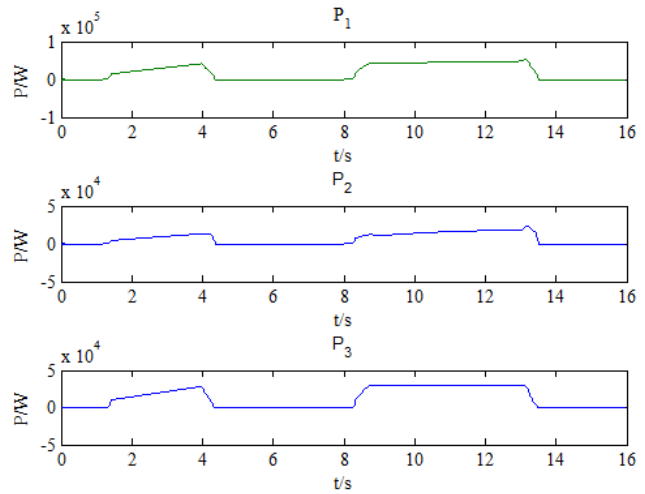

Figure 19: Power

\subsection{Torque coupling device model}

Torque coupling device is shown in Fig. 20, where Port 1 is connected to Port 2 of speed coupler with unidirectional energy flow, Ports 2 is connected to the motor drive with bidirectional energy flow and Port 3 is connected to the vehicle with bidirectional energy flow.

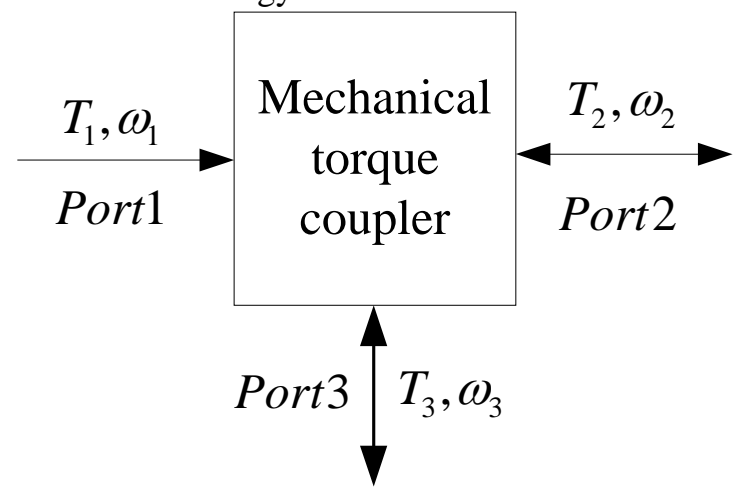

Figure 20: Torque coupling

The mechanical torque coupler has the property shown in (4), where $k_{1}$ and $k_{2}$ are constants associated with the structural and geometric design of torque coupling device. 


$$
\left\{\begin{array}{l}
T_{3}=k_{1} T_{1}+k_{2} T_{2} \\
\omega_{3}=\frac{\omega_{1}}{k_{1}}=\frac{\omega_{2}}{k_{2}}
\end{array}\right.
$$

Simulation results of torque coupling are shown in Fig. 21 and Fig. 22.
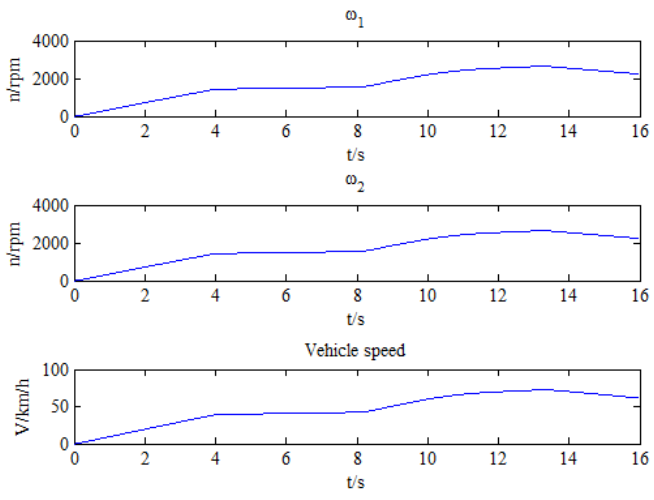

Figure 21: Speed

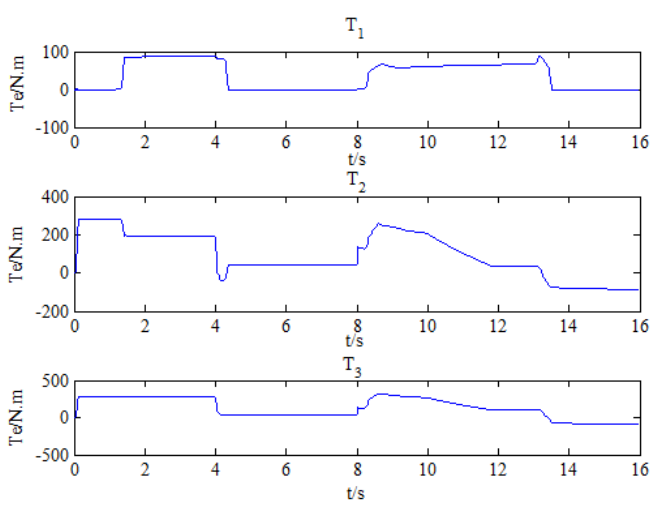

Figure 22: Torque

\section{Control Scheme of HEV}

The control scheme of HEV is shown in Fig. 23. According to Fig. 23, we can get the followings: If reference power is negative (braking mode), the HEV is in pure electric driving mode: the ICE is off. The reference ICE torque and generator torque are zero. The vehicle is only driven by motor and motor is working as generator to convert vehicle kinetic energy to electrical energy to charge battery.

If reference power is positive, the vehicle is cruising. If the reference power is more than the upper limit, the HEV is in hybrid drive mode: the ICE is on. The ICE power is divided into two parts by planetary gear unit. One part drives the vehicle through torque coupling device and the other drives the generator to generate electricity supplied to the motor. And the ICE torque and generator torque are in a fixed ratio.
If reference power is positive and less than the upper limit and the SOC is less than the lower limit, the HEV is also in hybrid drive mode. At this time, one part of ICE power drives the vehicle and the other drives the generator to generate electricity supplied to the motor and charge battery.

If reference power is positive and less than the upper limit and the SOC is more than the lower limit, the HEV is in pure electric driving mode. At this time, the vehicle is only driven by motor.

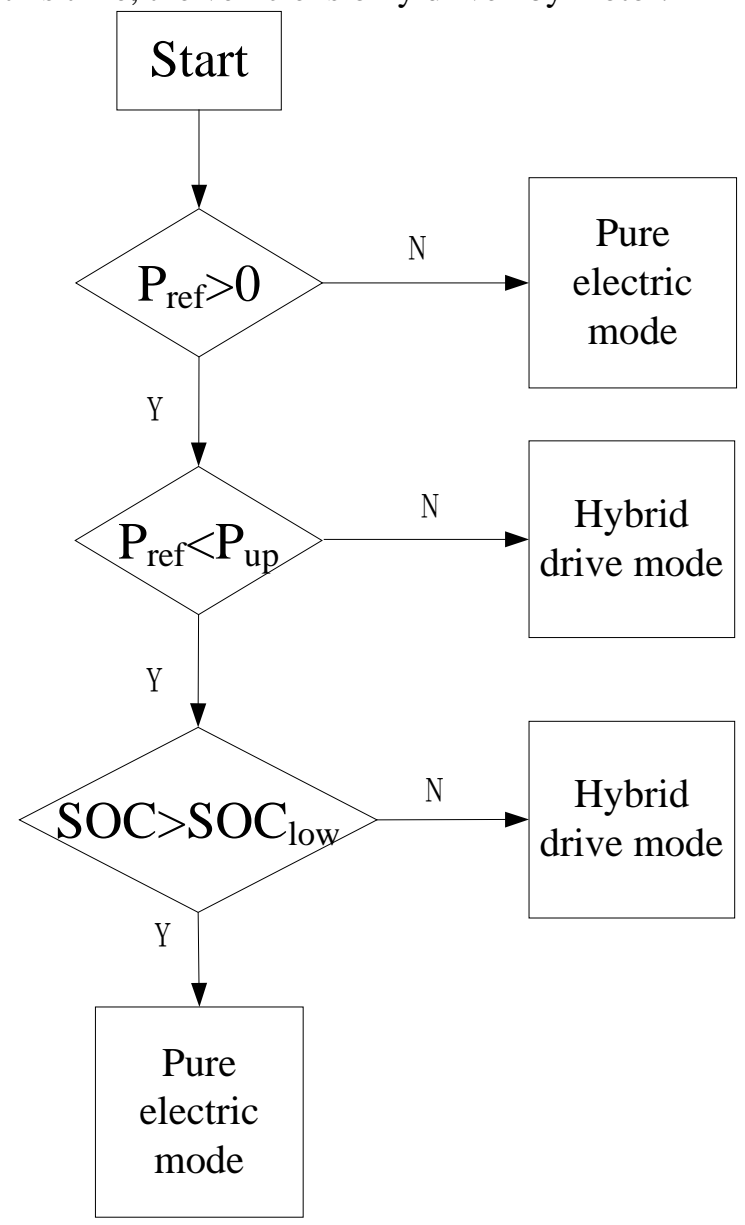

Figure 23: Control scheme of HEV

\section{Simulation results}

The accelerator position signal is shown in Fig. 24. And simulation result of hybrid signal, ICE torque, motor torque, generator torque, $\mathrm{T}_{2}$ of speed coupler, drive torque, motor power, generator power, battery power, SOC of battery and vehicle speed are shown in Fig. 25 to Fig. 35. 


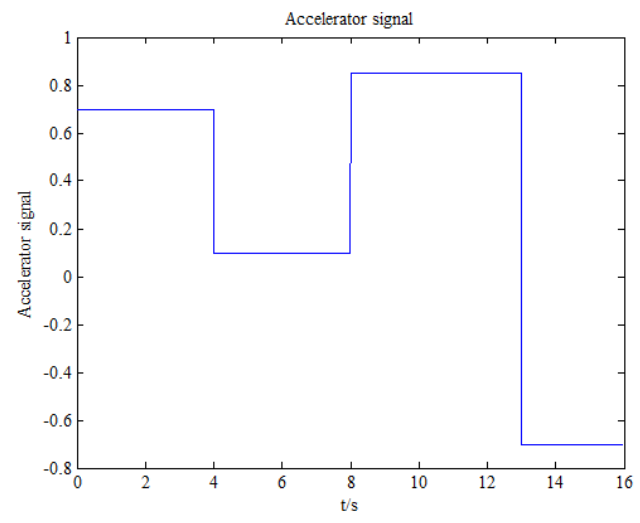

Figure 24: Accelerator signal

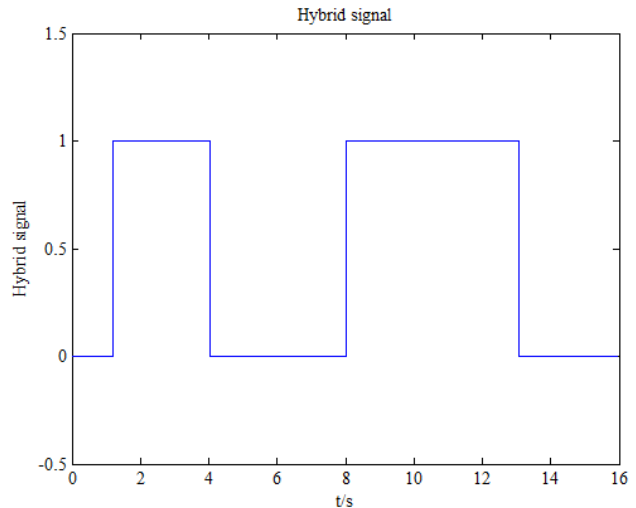

Figure 25: Hybrid signal

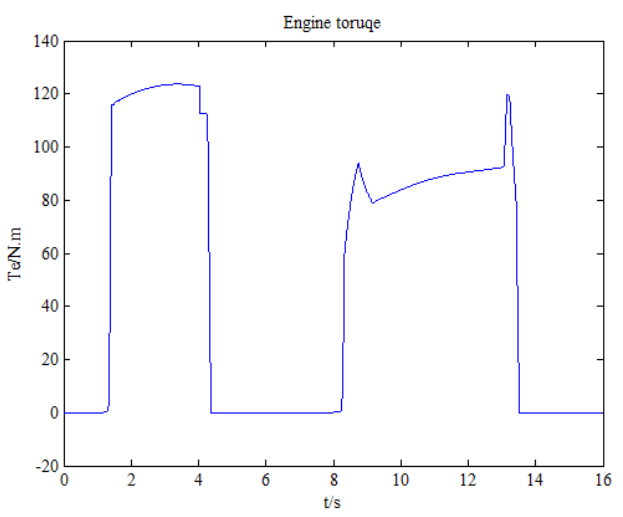

Figure 26: ICE torque

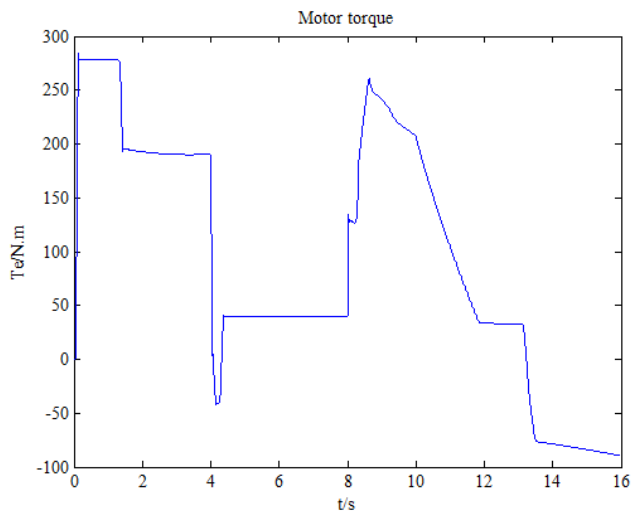

Figure 27: Motor torque

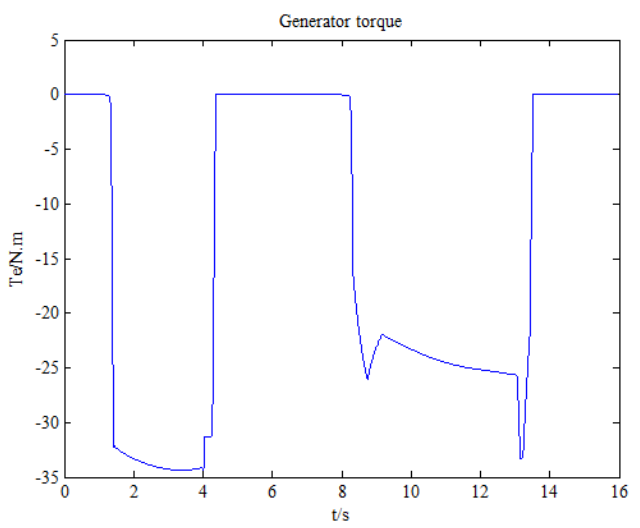

Figure 28: Generator torque

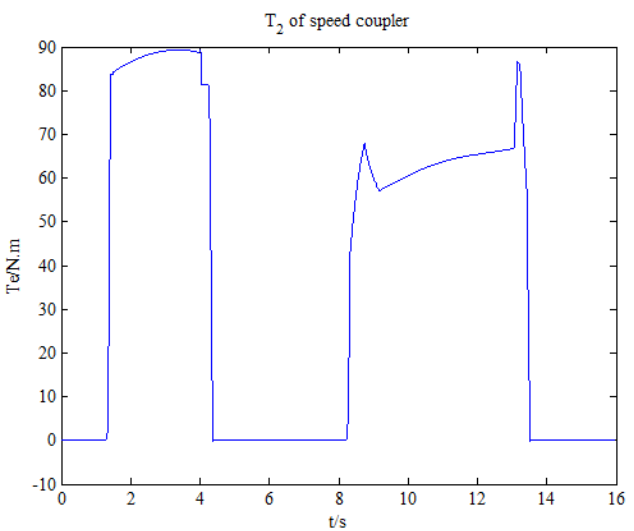

Figure 29: $T_{2}$ of speed coupler

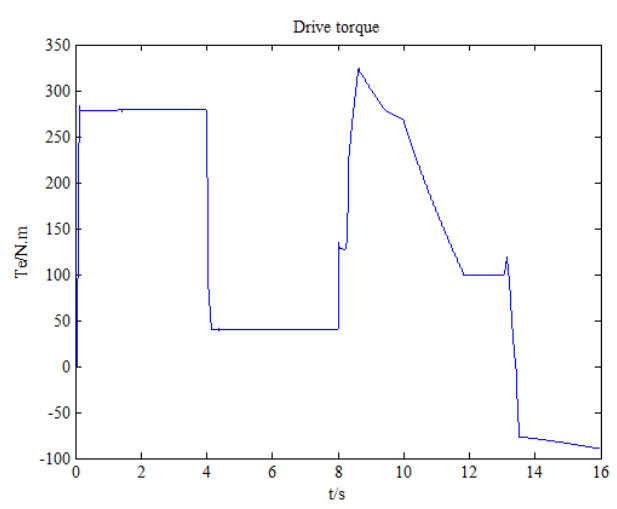

Figure 30: Drive torque

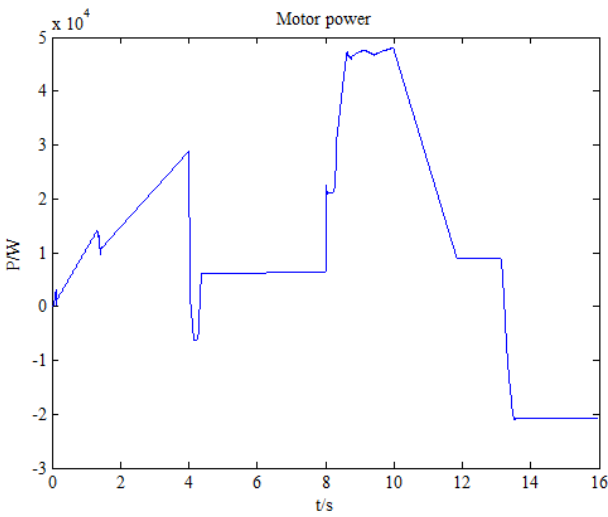

Figure 31: Motor power 


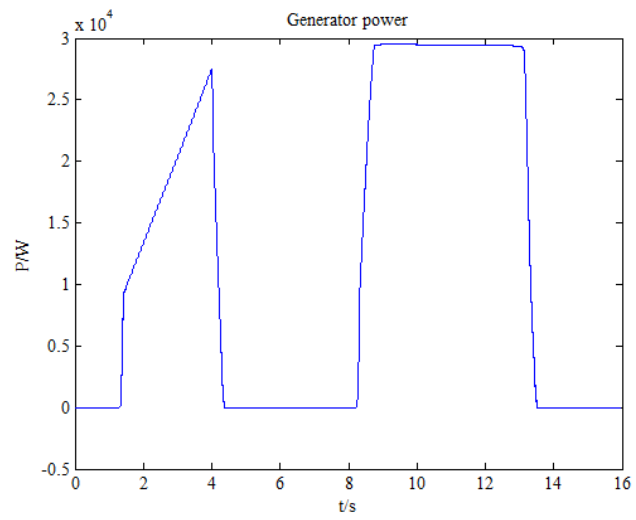

Figure 32: Generator power

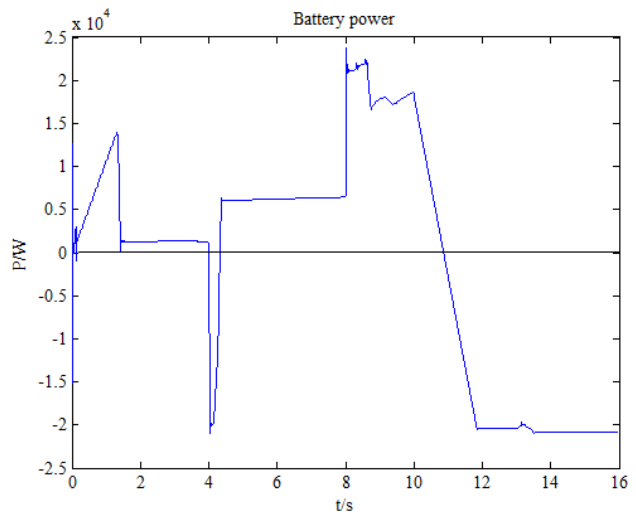

Figure 33: Battery power

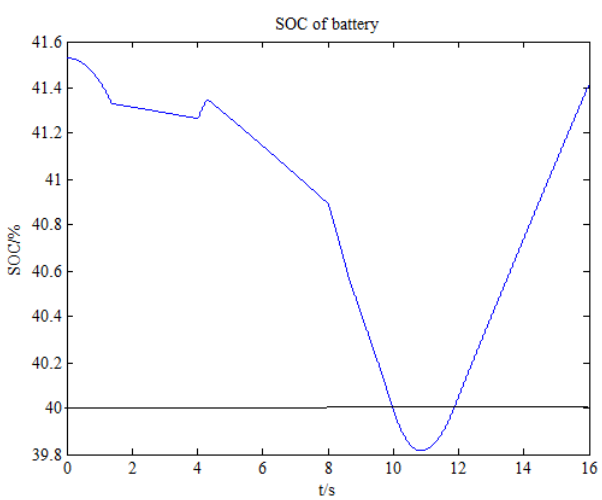

Figure 34: SOC of battery

Vehicle speed

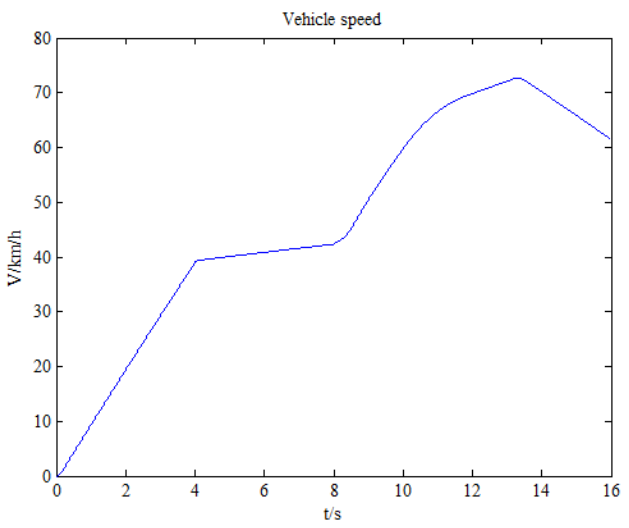

Figure 35: Vehicle speed
During $(0,1.18 \mathrm{~s})$, as reference power is positive and less than the upper limit $(12 \mathrm{~kW})$ and the SOC of battery is more than the lower limit (40\%) the HEV is in pure electric model. Hybrid signal is 0. ICE torque, generator torque and $\mathrm{T}_{2}$ of speed coupler are 0 . Vehicle is driven only by motor torque, so drive torque is equal to motor torque. Battery supplies power to motor to drive vehicle. So motor power is equal to battery power and the SOC of battery drops during this period.

During (1.18s, 4.05s), with the increase of reference torque and speed, the reference power is more than the upper limit, so the HEV is in hybrid drive model. Hybrid signal is 1 . ICE torque and $T_{2}$ of speed coupler is positive and generator torque is negative. Vehicle is driven by both motor torque and part of ICE torque ( $T_{2}$ of speed coupler), so drive torque is equal to the sum of motor torque and $T_{2}$ of speed coupler. Both battery and generator supply motor, so motor power is equal to the sum of motor torque and battery power.

During (4.05s, 8.01s), with the decrease of reference torque, the reference power is less than the upper limit, so the hybrid signal indicates that the HEV is in pure electric model: vehicle is driven only by motor. But ICE can't stop producing torque at once. Actually, during (4.05s, 4.37s), ICE still generates torque.

During (4.05s, 4.06s), the HEV is still in hybrid drive model. Vehicle is driven by both motor torque and $\mathrm{T}_{2}$ of speed coupler. Both battery and generator supply motor.

During (4.06s, 4.32s), motor operates as a generator in order to decrease speed rapidly, which generates electricity to charge battery. So motor torque, motor power and battery power are negative. During this period, both generator and motor supply power to battery, so the SOC of battery rises during this period. And only $\mathrm{T}_{2}$ of speed coupler drives vehicle.

During (4.32s, 4.37s), vehicle is driven by both motor torque and $T_{2}$ of speed coupler. Both battery and generator supply motor.

During (4.37s, 8.01s), the HEV is only driven by motor. Battery supplies motor to drive vehicle.

During (8.05s, 13.08s), with the increase of reference power, the HEV is again in hybrid drive model. But ICE also can't produce torque instantaneously and during (8.05s, 8.22s), the ICE doesn't output torque.

During (8.05s, 8.22s), the HEV is only driven by motor. Battery supplies motor to drive vehicle.

During (8.22s, 10.85s), the HEV is in hybrid drive model. Vehicle is driven by both motor torque and 
$\mathrm{T}_{2}$ of speed coupler. Both battery and generator supply motor.

During (10.85s, 13.08s), the HEV is still in hybrid drive model and vehicle is driven by both motor torque and $\mathrm{T}_{2}$ of speed coupler. But generator supplies power to motor and charges battery. So the SOC of battery rises during this period. In fact, at $t=9.99 \mathrm{~s}$, the SOC of battery is less than the lower limit (40\%). But in order to satisfy the demand of vehicle, during (9.99s, $10.85 \mathrm{~s})$, battery still supplies power to motor.

During (13.08s, 16s), the accelerator position signal and the reference power are negative, so the hybrid signal indicates that the HEV is again in pure electric model. But as ICE can't stop working at once, during (13.08s, 13.52s), the $\mathrm{HEV}$ is still in hybrid drive model.

During (13.08s, 13.22s), vehicle is driven by both motor torque and $T_{2}$ of speed coupler. Generator supplies power to motor and charges battery.

During (13.22s, 13.52s), motor operates as a generator. Vehicle is only driven by $T_{2}$ of speed coupler. Both motor and generator charge battery. During (13.52s, 16s), the HEV is in pure electric model. ICE stops working. Motor is driven by vehicle and operates a generator to charge battery.

\section{Conclusions}

In this paper, a series-parallel HEV model is built by using Matlab/Simlunk, which includes vehicle longitudinal dynamics model, tire model, an ICE model, battery model, a DC/DC converter model, a motor drive model, a generator drive model, a speed coupling device model (planetary gear mechanism), and a torque coupler device model. Control scheme of HEV is presented. And Simulation results testify the effectiveness of the HEV model.

\section{Acknowledgments}

This work is supported by National Natural Science Foundation (NNSF) of China under Grant 51207012 and Key Laboratory of Small \& Special Motor and Drive Technology of Shanxi Province under the Grant 2013SSJ2002.

\section{References}

[1] C. C. Chan, The state of the art of electric and hybrid vehicles, Proc. IEEE, vol. 90, no. 2, pp. 247-275, Feb. 2002
[2] K. Yamada, H. Hanada, and S. Sasaki, The motor control technologies for GS450h hybrid system, in Proc. EVS-22, Yokohama, Japan, Oct. 2006, pp. 827-835.

[3] C. C. Chan and K. T. Chau, Modern Electric Vehicle Technology. Oxford, U.K. Oxford Univ. Press.

[4] Mehrdad Ehsani, Yimin Gao and Ali Emadi. Modern Electric, Hybrid Electric, and Fuel Cell Vehicles Fundamentals, Theory, and Design, CRC Press.

[5] SALMASI F R. Control strategies for hybrid electric vehicles: evolution, classification, comparison, and future trends, IEEE Transactions on Vehicular Technology, 2007.

\section{Authors}

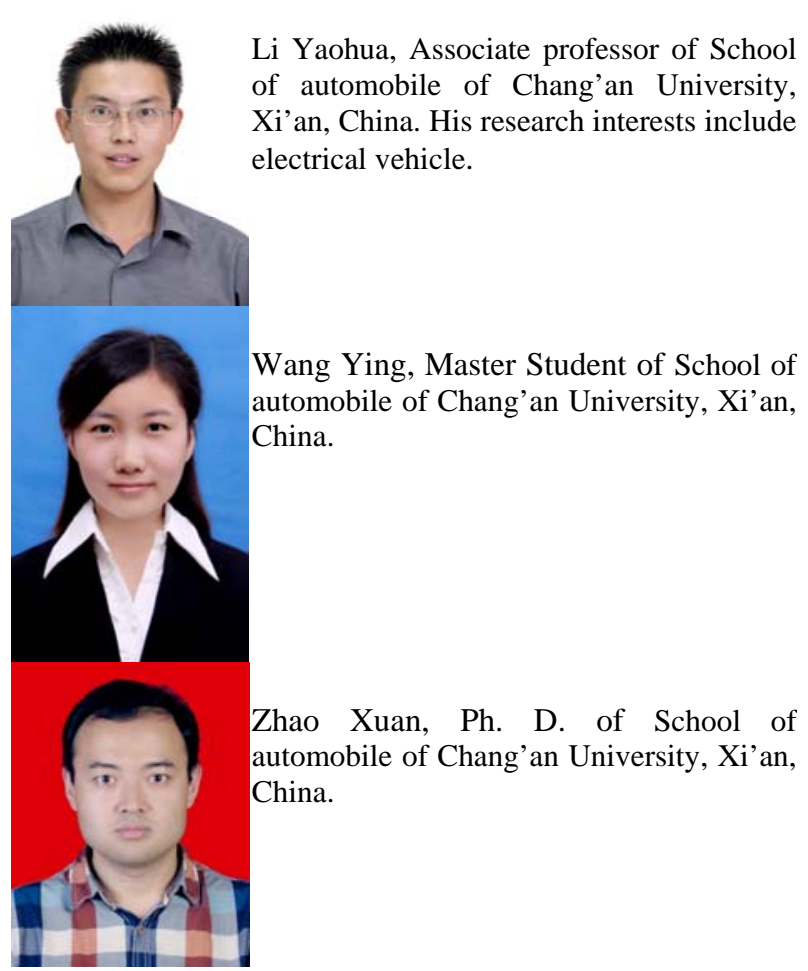

